\title{
The Frequency of, and Factors Associated with Prolonged Hospitalization: A Multicentre Study in Victoria, Australia
}

\author{
Richard Ofori-Asenso ${ }^{1,2}$, Danny Liew ${ }^{1}$, Johan Mårtensson ${ }^{3}$ and Daryl Jones ${ }^{1,4, *}$ \\ 1 Department of Epidemiology and Preventive Medicine, School of Public Health and Preventive Medicine, \\ Monash University, Melbourne, VIC 3800, Australia; asensox215@gmail.com (R.O.-A.); \\ Danny.liew@monash.edu (D.L.) \\ 2 Department of Pharmacy, Faculty of Health and Medical Sciences, University of Copenhagen, \\ 1165 Copenhagen, Denmark \\ 3 Department of Physiology and Pharmacology, Section of Anaesthesia, and Intensive Care, \\ Karolinska Institutet, 17177 Stockholm, Sweden; johan.martensson@sll.se \\ 4 Department of Intensive Care Austin Hospital, Melbourne, VIC 3084, Australia \\ * Correspondence: Daryl.Jones@monash.edu; Tel.: +61-394-965-057; Fax: +61-394-963-932
}

Received: 18 August 2020; Accepted: 17 September 2020; Published: 22 September 2020

check for updates

\begin{abstract}
Background: Limited available evidence suggests that a small proportion of inpatients undergo prolonged hospitalization and use a disproportionate number of bed days. Understanding the factors contributing to prolonged hospitalization may improve patient care and reduce the length of stay in such patients. Methods: We undertook a retrospective cohort study of adult ( $\geq 20$ years) patients admitted for at least $24 \mathrm{~h}$ between 14 November 2016 and 14 November 2018 to hospitals in Victoria, Australia. Data including baseline demographics, admitting specialty, survival status and discharge disposition were obtained from the Victorian Admission Episode Dataset. Multivariable logistic regression analysis was used to identify factors independently associated with prolonged hospitalization ( $\geq 14$ days). Cox proportional hazard regression model was used to examine the association between various factors and in-hospital mortality. Results: There were almost 5 million hospital admissions over two years. After exclusions, 1,696,112 admissions lasting at least $24 \mathrm{~h}$ were included. Admissions with prolonged hospitalization comprised only $9.7 \%$ of admissions but utilized $44.2 \%$ of all hospital bed days. Factors independently associated with prolonged hospitalization included age, female gender, not being in a relationship, being a current smoker, level of co-morbidity, admission from another hospital, admission on the weekend, and the number of admissions in the prior 12 months. The in-hospital mortality rate was $5.0 \%$ for those with prolonged hospitalization compared with $1.8 \%$ in those without $(p<0.001)$. Prolonged hospitalization was also independently associated with a decreased likelihood of being discharged to home (OR 0.53, 95\% CI 0.52-0.54). Conclusions: Patients experiencing prolonged hospitalization utilize a disproportionate proportion of bed days and are at higher risk of in-hospital death and discharge to destinations other than home. Further studies are required to identify modifiable factors contributing to prolonged hospitalization as well as the quality of end-of-life care in such admissions.
\end{abstract}

Keywords: hospitalization; bed utilization; mortality; length of stay

\section{Introduction}

There are competing demands for the provision of healthcare in modern hospitals of resource-rich countries. On the one hand, the population is ageing, and hospitalized patients have increased co-morbidity and complexity of disease [1-4]. Thus, hospitals continue to account for a significant 
proportion of health expenditure, with about two-fifths of health spending among The Organisation for Economic Co-operation and Development (OECD) countries devoted to hospital care [5].

On the other hand, there is a need to ensure the sustainability of hospitals by reducing hospital length of stay (LOS), optimizing utilisation of available resources, and minimizing the risk of nosocomial complications [6]. Studies have suggested that a significant proportion of inpatient days in modern hospitals are inappropriate $[7,8]$. Reducing medically inappropriate days in hospital could substantially lower the cost of providing hospital services $[9,10]$. Consequently, LOS has emerged as one of the key performance indicators in developed countries of hospital efficiency. In particular, improvements in LOS could free up beds and staff time and contribute to better provision and efficient use of hospital resources to address population health needs.

Several studies have identified factors associated with protracted hospitalization, but many of these have focused on targeted patient populations [11-40] or involved data collected at a single centre $[13,18,19,23,24,28,29,31,37,39-45]$ Understanding the factors that contribute to prolonged hospitalization in a broader patient cohort may guide the development of interventions that target at risk patients, improve overall care, and reduce resource utilisation.

A recently published single-centre study from a large tertiary referral teaching hospital in Australia revealed that only $13.1 \%$ of hospital admissions lasted at least 14 days, but that such admissions accounted for $49.1 \%$ of all bed days [44]. This study identified several baseline factors associated with prolonged hospitalization and reported prolonged hospitalization to be associated with a 2.6-fold increased risk of in-hospital death [44]. Accordingly, we conducted a retrospective cohort study of all hospital admissions in the state of Victoria in Australia to evaluate the frequency of, and factors associated with prolonged hospitalization. In addition, we sought to determine if prolonged hospitalization was associated with an increased risk of in-hospital death.

\section{Methods}

\subsection{Ethics Approval}

The conduct of the study was approved by the Monash University Human Research Ethics Committee (Project \#: 14204), as well as the Victorian Department of Health and Human Services (DHHS) data privacy approver, as part of the data Custodian Approval process.

\subsection{Study Design and Participants}

We conducted a retrospective cohort study using data collected between 14 November 2016 and 14 November 2018. We included all admission episodes (unit of analysis) involving patients aged $\geq 20$ years admitted to acute care facilities across all of Victoria, Australia. We excluded same-day admissions (those lasting less than one calendar day), as well as admissions related to childbirth. In addition, we excluded patients with missing admission diagnoses, short term admissions related to dialysis, and patients who had an admission involving discharge to the "hospital in the home" service [46]. Patients who had an admission involving discharge to the "hospital in the home" service were excluded as they receive low level intensity of treatment in their own homes, often for extended periods. As the focus of the study was to examine utilization of acute hospital beds, such patients were not thought to be representative of acutely unwell hospitalized patients and may have skewed the overall proportion of patients with prolonged LOS.

\subsection{Data Sources and Variables Collected}

Data were obtained from the Victorian Admissions Episodes Dataset (VAED) [46] and the Victorian Emergency Minimum Dataset (VEMD) [47]. These are administrative databases that capture all inpatient and emergency department (ED) encounters, respectively, for hospitals (public and private) in Victoria. Data are entered by dedicated and trained hospital staff and maintained by the Victorian DHHS. We extracted data related to the hospital type (private, regional, secondary, 
tertiary other as classified by the Victorian health authority), gender, age (provided in five-year age-groups), variables needed to calculate the Charlson co-morbidity index [48], smoking status, the number of hospital admissions in the past 12 months, Indigenous Australian status, marital status, emergency admission status, admission source, admission into the intensive care unit (ICU), and the time, day and season of admission. The length of stay used in the analysis was the duration of each hospital admission. If a patient was transferred from one hospital to another, then they had two records, each with an LOS. The second record would be coded as a transfer from another hospital. As the dataset did not allow for linkage of episodes of care provided at different hospitals in patients who were transferred, we adjusted for the source of admission (e.g., home, from another hospital, etc.). Private hospitals are defined as hospitals not funded or managed by the Victorian Department of health and human services. Publicly funded and managed hospitals include regional (country or non-metropolitan), secondary (medium sized metropolitan hospitals with limited specialty services) and tertiary (large University-affiliated hospitals with a wide range of specialty services). Admission diagnosis was also collected, based on the Australian refined diagnostic related group (DRG) classification of the primary diagnosis (AR-DRG v9.0) [46], and was categorized into one of 37 specialties based on the classification system used in the VAED (Supplementary Table S1) [46]. The 37 specialties were ranked and ordered according to the corresponding length of stay. They were then divided into four groups based on this ranking (numbered 1-4).

\subsection{Outcomes}

The primary outcomes (dependent variables) were prolonged hospitalization and in-hospital mortality. There is no accepted or consensus definition of what constitutes prolonged LOS. In keeping with other published studies [13,44], we chose a duration of 14 days. This period is relevant from both a clinical perspective and with regard to resource utilization. Importantly, it was defined a priori. Secondary outcomes were the proportion of overall bed days incurred by prolonged hospitalizations, as well as the proportion of patients discharged to home. The independent variables included in the logistic regression and Cox proportional models were the patients' demographic and clinical parameters.

\subsection{Statistical Analysis}

Descriptive statistics were used to summarise the baseline characteristics of the study population. A chi-squared test was used to compare all baseline categorical variables between patients who experienced prolonged hospitalization and those who did not, and those who died in hospital and those who survived.

Univariate and multivariable logistic regression analyses were used to examine the associations between the various factors and prolonged length of hospitalization and discharge to home. In each of the multivariable analyses, all variables were entered simultaneously into the model. Additional sensitivity analysis was performed to confirm the various factors associated with prolonged hospitalization by restricting the analysis to only survivors.

In all models, multicollinearity was assessed using the variation inflation factor (VIF) in which values $>3$ indicates collinearity between the variables. No parameter was dropped as per the VIF values. The association between various factors and in-hospital mortality was assessed via Cox proportional hazards model. In both the logistic and Cox proportional hazards models, for age comparisons, a mid-point age (60-64 years) was selected as the reference group to distinguish older adults from younger individuals [49]. All analyses were performed using STATA 16/SE (StataCorp, College Station, TX, USA). A two-tailed $p$-value of $<0.05$ was considered statistically significant. 


\section{Results}

\subsection{Details of Study Cohort}

During the two-year study period, there were 4.99 million admission cases. After exclusions, there were 1,696,112 admissions lasting at least $24 \mathrm{~h}$ (Figure 1). The median LOS was 3 (IQR 1-6) days. Overall, 51.7\% of admissions occurred in females, and patients aged at least 65 years comprised $51.8 \%$ of the cohort. The majority (56.3\%) of patients were in a relationship at the time of admission, and most were admitted from home (85.0\%) and on weekdays (66.2\%). Admissions were medical in $61.6 \%$ of cases and $49.5 \%$ were classified as emergency admissions (Table 1 ).

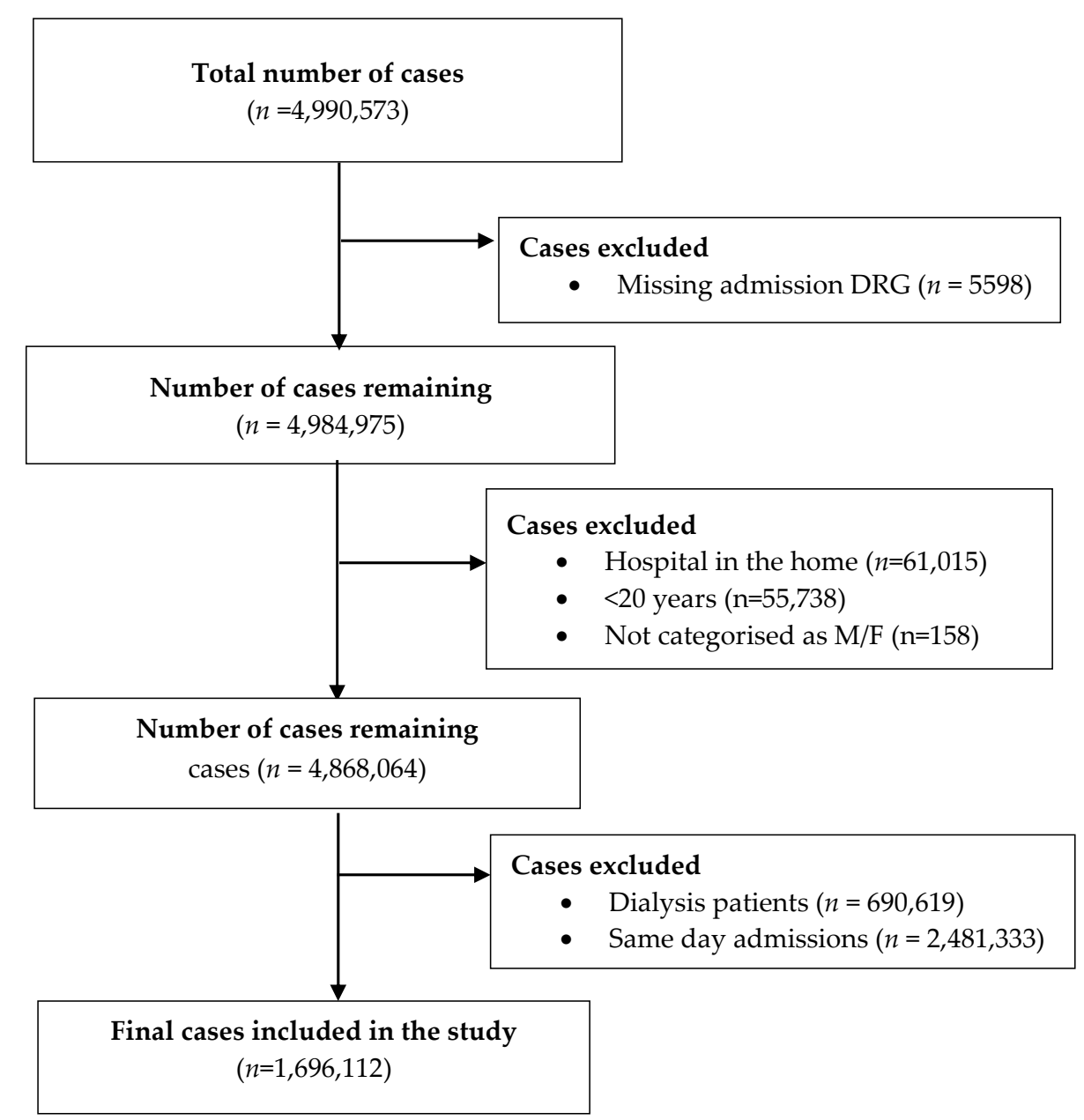

Figure 1. Details of multi-stay admissions included in the study following exclusion of admissions with missing data, same-day admissions, admissions associated with hospital in the home care, and patients less than 20 years. DRG = diagnostic related group, $\mathrm{M}=$ male, $\mathrm{F}=$ female. 
Table 1. Characteristics of patients hospitalized over two years in Victoria, Australia.

\begin{tabular}{|c|c|c|c|}
\hline \multirow{2}{*}{ Variable } & \multirow{2}{*}{ Overall } & \multicolumn{2}{|c|}{ Period } \\
\hline & & 14 Nov. 2016-13 Nov. 2017 & 14 Nov. 2017-14 Nov. 2018 \\
\hline Number of cases ( $n$ ) & $1,696,112$ & 834,045 & 862,067 \\
\hline Female $(n, \%)$ & $877,020(51.7)$ & $431,543(51.7)$ & $445,477(51.7)$ \\
\hline \multicolumn{4}{|l|}{ Age groups, years. $(n, \%)$} \\
\hline $20-24$ & $61,465(3.6)$ & $30,666(3.7)$ & $30,799(3.6)$ \\
\hline $25-29$ & $65,547(3.9)$ & $32,465(3.9)$ & $33,082(3.8)$ \\
\hline $30-34$ & $72,766(4.3)$ & $35,991(4.3)$ & $36,775(4.3)$ \\
\hline $35-39$ & $75,571(4.5)$ & $37,261(4.5)$ & $38,310(4.4)$ \\
\hline $40-44$ & $82,135(4.8)$ & $41,519(5.0)$ & $40,616(4.7)$ \\
\hline $45-49$ & $95,566(5.6)$ & $47,104(5.7)$ & $48,462(5.6)$ \\
\hline $50-54$ & $103,747(6.1)$ & $51,793(6.2)$ & $51,954(6.0)$ \\
\hline $55-59$ & $121,095(7.1)$ & $59,470(7.1)$ & $61,625(7.2)$ \\
\hline $60-64$ & $137,130(8.1)$ & $67,467(8.1)$ & $69,663(8.1)$ \\
\hline $65-69$ & $163,254(9.6)$ & $81,217(9.7)$ & $82,037(9.5)$ \\
\hline $70-74$ & $170,359(10.0)$ & $81,641(9.8)$ & $88,718(10.3)$ \\
\hline $75-79$ & $168,124(9.9)$ & $82,130(9.9)$ & $85,994(10.0)$ \\
\hline $80-84$ & $158,335(9.3)$ & $77,411(9.3)$ & $80,924(9.4)$ \\
\hline$\geq 85$ & $221,018(13.0)$ & $107,910(12.9)$ & $113,108(13.1)$ \\
\hline Indigenous population $(n, \%)$ & $13,888(0.8)$ & $6604(0.8)$ & $7284(0.8)$ \\
\hline \multicolumn{4}{|l|}{ Marital Status $(n, \%)$} \\
\hline Never married & $325,672(19.2)$ & $160,081(19.2)$ & $165,591(19.2)$ \\
\hline Widowed & $244,190(14.4)$ & $120,811(14.5)$ & $123,379(14.3)$ \\
\hline Married or defacto & $955,280(56.3)$ & $470,118(56.4)$ & $485,162(56.3)$ \\
\hline Divorced or separated & $143,222(8.4)$ & $69,762(8.4)$ & $73,460(8.5)$ \\
\hline Other & $27,748(1.6)$ & $13,273(1.6)$ & $14,475(1.7)$ \\
\hline \multicolumn{4}{|l|}{ DRG type } \\
\hline Medical & $1,044,369(61.6)$ & $508,577(61.0)$ & $535,792(62.2)$ \\
\hline Surgical & $571,449(33.7)$ & $285,911(34.3)$ & $285,538(33.1)$ \\
\hline Other & $80,294(4.7)$ & $39,557(4.7)$ & $40,737(4.7)$ \\
\hline Emergency admission $(n, \%)$ & $839,360(49.5)$ & $405,571(48.6)$ & $433,789(50.3)$ \\
\hline \multicolumn{4}{|l|}{ Admission source $(n, \%)$} \\
\hline Home & $1,442,065(85.0)$ & $710,111(85.1)$ & $731,954(84.9)$ \\
\hline Aged care residential facility & $11,302(0.7)$ & $5234(0.6)$ & $6068(0.7)$ \\
\hline From another hospital & $195,230(11.5)$ & $95,892(11.5)$ & $99,338(11.5)$ \\
\hline Other & $47,515(2.8)$ & $22,808(2.7)$ & $24,707(2.9)$ \\
\hline ICU stay $(n, \%)$ & $79,115(4.7)$ & $39,187(4.7)$ & $39,928(4.6)$ \\
\hline Admitted on weekend $(n, \%)$ & $573,292(33.8)$ & $282,965(33.9)$ & $290,327(33.7)$ \\
\hline \multicolumn{4}{|l|}{ Season of admission $(n, \%)$} \\
\hline Spring (Sep-Nov) & $406,209(24.0)$ & $204,835(24.6)$ & $201,374(23.4)$ \\
\hline Summer (Dec-Feb) & $415,172(24.5)$ & $203,530(24.4)$ & $211,642(24.6)$ \\
\hline Autumn (Mar-May) & $433,328(25.6)$ & $209,706(25.1)$ & $223,622(25.9)$ \\
\hline Winter (Jun-Aug) & $441,403(26.0)$ & $215,974(25.9)$ & $225,429(26.2)$ \\
\hline \multicolumn{4}{|l|}{ Prior admissions in 12 months } \\
\hline 0 & $711,166(41.9)$ & $411,233(49.2)$ & $300,379(34.8)$ \\
\hline 1 & $374,576(22.1)$ & $186,092(22.3)$ & $188,760(21.9)$ \\
\hline$\geq 2$ & $610,370(36.0)$ & $238,009(28.5)$ & $372,928(43.3)$ \\
\hline \multicolumn{4}{|l|}{$\begin{array}{l}\text { Risk category based on } \\
\text { admission unit }\end{array}$} \\
\hline 1 & $659,004(38.9)$ & $324,467(38.8)$ & $334,991(38.9)$ \\
\hline 2 & $503,703(29.7)$ & $245,034(29.3)$ & $259,133(30.1)$ \\
\hline 3 & $387,474(22.8)$ & $192,039(23.0)$ & $195,701(22.7)$ \\
\hline 4 & $145,931(8.6)$ & $73,794(8.8)$ & $72,242(8.4)$ \\
\hline In-hospital mortality $(n, \%)$ & $35,287(2.1)$ & $17,535(2.1)$ & $17,752(2.1)$ \\
\hline \multicolumn{4}{|l|}{ Length of stay (days), $(n, \%)$} \\
\hline $1-6$ & $1284,508(75.7)$ & $629,370(75.5)$ & $655,138(76.0)$ \\
\hline $7-13$ & $248,154(14.6)$ & $122,166(14.7)$ & $125,988(14.6)$ \\
\hline $14-20$ & $83,037(4.9)$ & $41,317(5.0)$ & $41,720(4.8)$ \\
\hline $21-27$ & $35,457(2.1)$ & $17,696(2.1)$ & $17,761(2.1)$ \\
\hline$\geq 28$ & $44,956(2.7)$ & $23,496(2.8)$ & $21,460(2.5)$ \\
\hline
\end{tabular}

$\mathrm{DRG}=$ diagnostic related group; ICU = intensive care unit. 


\subsection{Frequency of Prolonged Hospitalization and Details of Bed Utilisation}

The breakdown of hospital LOS and the corresponding utilisation of bed days is shown in Table 2 . Admissions with prolonged hospitalization comprised only $9.7 \%$ of admissions, but utilized bed days, representing $44.2 \%$ of all hospital bed days for multi-day admissions (Table 2).

Table 2. Details of bed utilization according to hospital length of stay and hospital type for patients hospitalized over two years in Victoria, Australia.

\begin{tabular}{|c|c|c|c|}
\hline Days of Stay & Hospital Type & Number (\%) Admissions * & Number (\%) Bed Days \\
\hline \multirow{6}{*}{ All length of stay } & Overall & $1,696,112(100)$ & $9,450,306(100.0)$ \\
\hline & Private & $608,815(35.9)$ & $327,285(34.6)$ \\
\hline & Regional & $207,938(12.3)$ & $1,148,083(12.1)$ \\
\hline & Secondary & $382,490(22.6)$ & $1,984,477(21.0)$ \\
\hline & Tertiary & $378,075(22.3)$ & $1,962,871(20.8)$ \\
\hline & Other & $118,794(7.0)$ & $1,082,050(11.4)$ \\
\hline \multirow{6}{*}{ LOS1-6 days } & Overall & $1,284,508(75.7)$ & $2,988,383(31.6)$ \\
\hline & Private & $450,324(74.0)$ & $1,047,298(32.0)$ \\
\hline & Regional & $160,939(77.4)$ & $386,284(33.6)$ \\
\hline & Secondary & $302,906(79.2)$ & $690,189(34.8)$ \\
\hline & Tertiary & $294,359(77.9)$ & $678,895(34.6)$ \\
\hline & Other & $75,980(64.0)$ & $185,717(17.2)$ \\
\hline \multirow{6}{*}{ LOS 7-13 days } & Overall & $248,154(14.6)$ & $2,285,159(24.2)$ \\
\hline & Private & $102,152(16.8)$ & $945,255(28.9)$ \\
\hline & Regional & $27,535(13.2)$ & $251,200(21.9)$ \\
\hline & Secondary & $48,214(12.6)$ & $441,094(22.2)$ \\
\hline & Tertiary & $51,832(13.7)$ & $475,350(24.2)$ \\
\hline & Other & $18,421(15.5)$ & $172,260(15.9)$ \\
\hline \multirow{6}{*}{ LOS $14-20$ days } & Overall & 83,037 (4.9) & $1,354,911(14.3)$ \\
\hline & Private & $32,485(5.3)$ & $524,364(16.0)$ \\
\hline & Regional & $9446(4.5)$ & 155,169 (13.5) \\
\hline & Secondary & $15,066(3.9)$ & $247,272(12.5)$ \\
\hline & Tertiary & $16,477(4.4)$ & $270,422(13.8)$ \\
\hline & Other & $9563(8.1)$ & $157,684(14.6)$ \\
\hline \multirow{6}{*}{ LOS $21-27$ days } & Overall & 35,457 (2.1) & $831,620(8.8)$ \\
\hline & Private & $11,866(1.9)$ & $2,77,342(8.5)$ \\
\hline & Regional & $4251(2.0)$ & $99,921(8.7)$ \\
\hline & Secondary & $6710(1.8)$ & $157,566(7.9)$ \\
\hline & Tertiary & $7121(1.9)$ & $167,133(8.5)$ \\
\hline & Other & 5509 (4.6) & $129,658(12.0)$ \\
\hline \multirow{6}{*}{ LOS $\geq 28$ days } & Overall & $44,956(2.7)$ & $1,990,233(21.1)$ \\
\hline & Private & $11,988(2.0)$ & 478,566 (14.6) \\
\hline & Regional & $5767(2.8)$ & $255,509(22.3)$ \\
\hline & Secondary & $9594(2.5)$ & $448,356(22.6)$ \\
\hline & Tertiary & $8286(2.2)$ & $371,071(18.9)$ \\
\hline & Other & $9321(7.8)$ & $436,731(40.4)$ \\
\hline
\end{tabular}

\subsection{Factors Associated with Prolonged Hospitalization}

Univariable associations of different factors with prolonged hospitalization are presented in Supplementary Table S2. There were clear differences in the median hospital length of stay according to the specialty classification (Figure 2). From the multivariable analysis, factors independently 
associated with prolonged hospitalization included age above 65 years, female gender, not being in a relationship, being a current smoker, emergency (unscheduled) admission status, admission from another hospital, admission on a weekend, increasing number of admissions in the prior 12 months and admission into the ICU (Table 3). Moreover, patients admitted for surgical reasons were less likely to experience prolonged hospital stay compared to medical admissions. When restricting the analysis to only survivors, similar factors were determined to be associated with prolonged hospitalization (Supplementary Table S3).

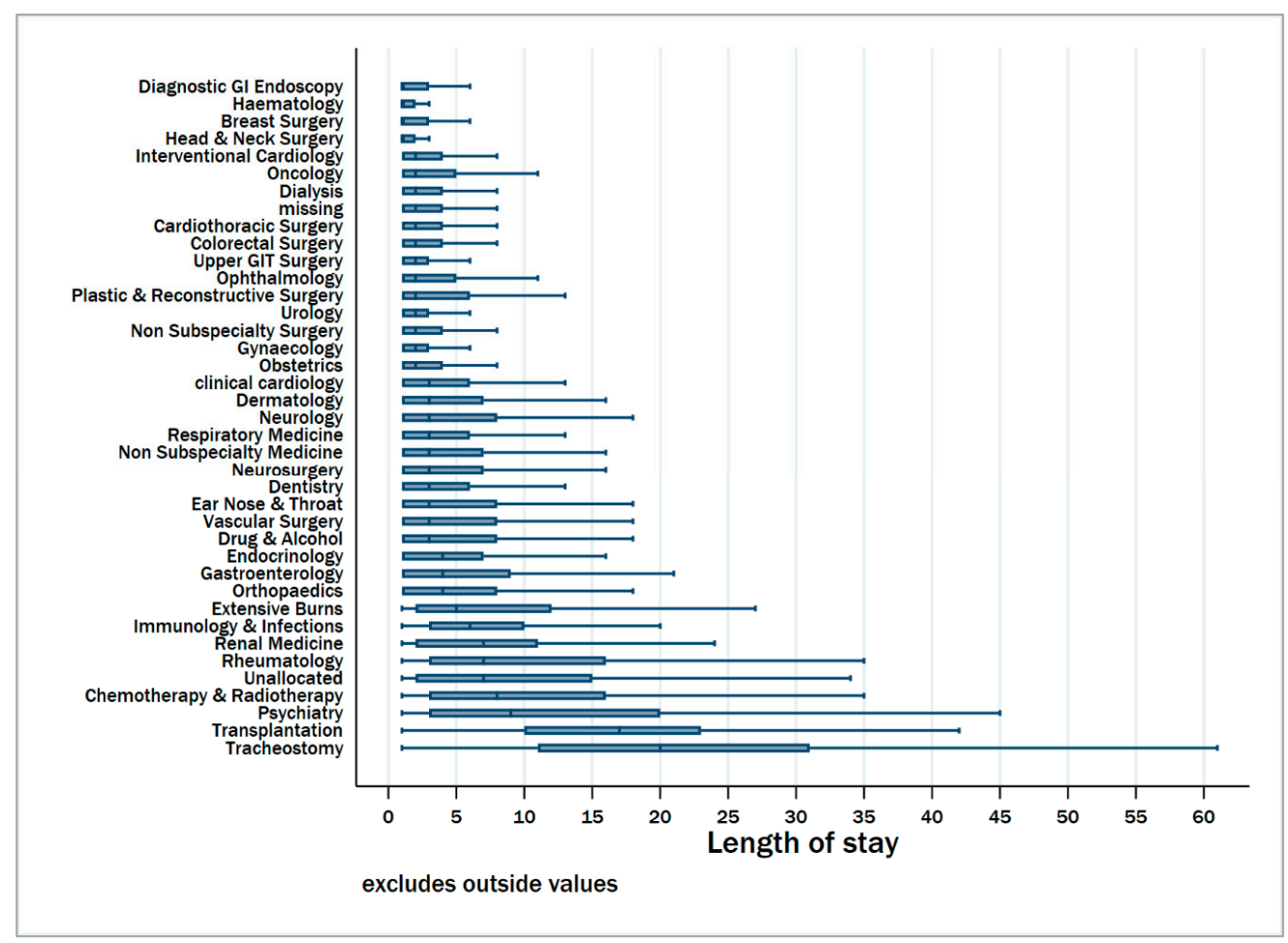

Figure 2. Boxplots showing median and inter-quartile length of hospital stay according to specialty services for patients hospitalized over two years in Victoria, Australia. Specialties are ranked according to increasing median length of stay. The risk categories were as follows. 1 (Diagnostic GI endoscopy-obstetrics); 2 (Clinical Cardiology-Drug \& alcohol); 3 (Endocrinology-immunology \& infections); 4 (Renal Medicine-Tracheostomy).

Table 3. Associations with prolonged hospitalization ( $\geq 14$ days) and in-hospital mortality for patients hospitalized over two years in Victoria, Australia.

\begin{tabular}{ccc}
\hline Variable & Longer LOS (Odds Ratio (OR), 95\% CI) & Mortality (Hazard Ratio (HR) 95\% CI) \\
\hline Age groups, years & & $0.22(0.18-0.29)$ \\
\hline $20-24$ & $0.74(0.71-0.78)$ & $0.26(0.21-0.32)$ \\
\hline $25-29$ & $0.85(0.81-0.88)$ & $0.32(0.27-0.38)$ \\
\hline $30-34$ & $0.97(0.93-1.01)$ & $0.40(0.35-0.46)$ \\
\hline $35-39$ & $1.01(0.97-1.05)$ & $0.56(0.50-0.63)$ \\
\hline $40-44$ & $0.97(0.94-1.01)$ & $0.70(0.64-0.77)$ \\
\hline $45-49$ & $0.95(0.92-0.99)$ & $0.80(0.74-0.87)$ \\
\hline $50-54$ & $0.96(0.93-0.99)$ & $0.91(0.85-0.97)$ \\
\hline $55-59$ & $0.95(0.92-0.98)$ & $1.0[$ reference] \\
\hline $60-64$ & $1.0[$ reference] & $1.08(1.02-1.14)$ \\
\hline $65-69$ & $1.03(1.00-1.06)$ & $1.18(1.12-1.24)$ \\
\hline $70-74$ & $1.16(1.13-1.19)$ & $1.32(1.25-1.39)$ \\
\hline $75-79$ & $1.47(1.43-1.51)$ & \\
\hline
\end{tabular}


Table 3. Cont.

\begin{tabular}{|c|c|c|}
\hline Variable & Longer LOS (Odds Ratio (OR), 95\% CI) & Mortality (Hazard Ratio (HR) 95\% CI) \\
\hline $80-84$ & $1.80(1.75-1.85)$ & $1.62(1.54-1.71)$ \\
\hline$\geq 85$ & $2.32(2.26-2.38)$ & $2.50(2.38-2.62)$ \\
\hline Female gender & $1.09(1.08-1.11)$ & $0.90(0.88-0.92)$ \\
\hline \multicolumn{3}{|l|}{ Indigenous population } \\
\hline Yes & $0.89(0.83-0.95)$ & $1.05(0.90-1.21)$ \\
\hline No & 1.0 [reference] & 1.0 [reference] \\
\hline Undefined & $1.13(1.07-1.19)$ & $1.34(1.22-1.47)$ \\
\hline \multicolumn{3}{|l|}{ Charlson co-morbidity Index } \\
\hline 0 & 1.0 [reference] & 1.0 [reference] \\
\hline $1-2$ & $1.44(1.42-1.46)$ & $2.74(2.63-2.85)$ \\
\hline $3-4$ & $2.04(2.00-2.09)$ & $4.27(4.09-4.46)$ \\
\hline $5-6$ & $2.15(2.07-2.23)$ & $6.15(5.81-6.50)$ \\
\hline$>6$ & $0.95(0.93-0.98)$ & $10.68(10.24-11.13)$ \\
\hline \multicolumn{3}{|l|}{ Marital Status } \\
\hline Never married & $1.59(1.56-1.61)$ & $0.89(0.86-0.93)$ \\
\hline Widowed & $1.26(1.23-1.28)$ & $0.95(0.92-0.97)$ \\
\hline Married or defacto & 1.0 [reference] & 1.0 [reference] \\
\hline Divorced or separated & $1.37(1.34-1.40)$ & $0.86(0.83-0.90)$ \\
\hline Other & $1.29(1.24-1.35)$ & $1.42(1.32-1.52)$ \\
\hline Current smoker & $1.26(1.24-1.28)$ & $0.87(0.83-0.91)$ \\
\hline \multicolumn{3}{|l|}{ DRG type } \\
\hline Medical & 1.0 [reference] & 1.0 [reference] \\
\hline Surgical & $0.60(0.59-0.61)$ & $0.28(0.26-0.29)$ \\
\hline Other & $0.79(0.76-0.82)$ & $1.09(1.04-1.14)$ \\
\hline $\begin{array}{l}\text { Emergency (unscheduled) } \\
\text { admission }\end{array}$ & $0.64(0.63-0.65)$ & $1.61(1.56-1.65)$ \\
\hline \multicolumn{3}{|l|}{ Admission source } \\
\hline Home & 1.0 [reference] & 1.0 [reference] \\
\hline Aged care residential facility & $0.97(0.90-1.04)$ & $2.49(2.33-2.67)$ \\
\hline From another hospital & $4.12(4.06-4.18)$ & $0.90(0.87-0.93)$ \\
\hline Other & $4.24(4.14-4.34)$ & $1.80(1.73-1.87)$ \\
\hline ICU stay & $3.38(3.31-3.45)$ & $3.17(3.06-3.28)$ \\
\hline Admitted on weekend & $1.07(1.05-1.08)$ & $0.94(0.91-0.96)$ \\
\hline \multicolumn{3}{|l|}{ Season of admission } \\
\hline Spring (Sep-Nov) & 1.0 [reference] & 1.0 [reference] \\
\hline Summer (Dec-Feb) & $1.17(1.15-1.19)$ & $0.96(0.93-0.99)$ \\
\hline Autumn (Mar-May) & $1.15(1.13-1.17)$ & $0.98(0.95-1.01)$ \\
\hline Winter (Jun-Aug) & $1.14(1.13-1.16)$ & $0.98(0.95-1.01)$ \\
\hline \multicolumn{3}{|l|}{ Prior admissions (in 12 months) } \\
\hline 0 & 1.0 [reference] & 1.0 [reference] \\
\hline 1 & $1.22(1.19-1.24)$ & $0.85(0.81-0.88)$ \\
\hline$\geq 2$ & $1.32(1.30-1.35)$ & $0.98(0.95-1.01)$ \\
\hline \multicolumn{3}{|l|}{$\begin{array}{l}\text { Risk category based on admission } \\
\text { unit }\end{array}$} \\
\hline 1 & 1.0 [reference] & 1.0 [reference] \\
\hline 2 & $1.86(1.83-1.89)$ & $0.91(0.87-0.94)$ \\
\hline 3 & $2.42(2.38-2.47)$ & $1.38(1.34-1.43)$ \\
\hline 4 & $8.39(8.22-8.56)$ & $2.59(2.50-2.69)$ \\
\hline Died in hospital & $0.90(0.87-0.93)$ & - \\
\hline
\end{tabular}

DRG = diagnostic related group, ICU = intensive care unit, LOS = length of stay. [reference], reference group. 


\subsection{Factors Associated with in-Hospital Mortality}

The in-hospital mortality rate for the overall cohort was $2.1 \%$. It was $1.8 \%$ in patients who stayed for less than 14 days, and 5.0\% for those with prolonged hospitalization $(p<0.001)$ (Supplementary Table S4). Factors independently associated with higher in-hospital mortality included increasing age, higher Charlson co-morbidity index and admission into a high-risk unit. Moreover, female gender was associated with a lower likelihood of in-hospital death (hazard ratio (HR) 0.90, 95\% CI 0.88-0.92) whereas ICU stay (HR 3.17, 95\% CI 3.06-3.28), and emergency (unscheduled) admission (HR 1.61, 95\% CI 1.56-1.65) were also associated with increased risk of in-hospital death (Table 3).

\subsection{Factors Associated with Hospital Discharge to Home}

Among survivors, $83.6 \%$ of patients were discharged to their private residence (Supplementary Table S5). Patients who experienced prolonged hospitalization were more likely to be discharged to a destination other than home compared with those without a prolonged hospitalization $36.5 \% \mathrm{vs}$. $14.4 \% ; p<0.001)$. After adjusting for other co-variates, prolonged hospitalization was associated with a decreased likelihood of being discharged to home (OR 0.53, 95\% CI (0.52-0.54)); (Supplementary Table S6). Moreover, other factors predicting admission to home included age, gender, admission source, ICU stay, season, and the risk category of the admitting unit.

\section{Discussion}

\subsection{Key Findings}

We conducted a retrospective cohort study of adult inpatients admitted for at least $24 \mathrm{~h}$ in Victoria over a two-year period to better understand the epidemiology of prolonged hospital admissions. We found that prolonged hospitalization comprised only one-tenth of multi-day admissions but accounted for nearly half of all bed days. Long stay patients were older, had greater co-morbidity, were more frequently admitted in the prior 12 months, and were more likely to be admitted under a medical unit. Moreover, such patients were more likely to die in hospital, and less likely to go home.

\subsection{Comparison with Previous Studies}

Most previous studies of prolonged hospitalization have focused on specific sub-groups of patients such as orthopaedic procedures [21,24,26,29-31,39], cardiovascular disease [13,15,17,36-38], solid organ transplantation $[33,50]$, or oncological conditions $[11,14,18,20,27,28,34,35]$ (Supplementary Table S7). A limited number of studies have examined the epidemiology of prolonged hospitalization in internal medicine patients $[23,45,51]$ but only one of these was multi-centre in nature [51]. Our study is one of few large multi-centre studies examining the characteristics of, and factors associated with prolonged hospitalization in a heterogenous population of patients.

In accordance with two previous studies, we defined prolonged hospitalization as an admission lasting at least 14 days $[13,44]$. This period is relevant from both a clinical perspective and in terms of healthcare utilization. Importantly, this cutoff was chosen a priori. Other studies have variably defined prolonged hospitalization as admissions lasting more than seven days $[19,23,29,37,38]$ or above the 75 th centile for length of stay $[11,12,14,15,17,20,26,27,30,40]$.

Relatively few studies have examined the proportion of overall bed days used by patients experiencing prolonged hospitalization. Using the same definition for prolonged hospitalization, O'Sullivan et al. conducted a single-centre study within the same jurisdiction as our study and similarly found that $13.1 \%$ of hospital admissions were at least 14 days, but used $49.1 \%$ of bed days [44]. Marfil-Garza et al. conducted a single-centre study in Mexico and found that $5.1 \%$ of admissions had a LOS more than 34 days but used $23.1 \%$ of total bed days [42]. Among general medicine discharges, Anderson et al. revealed that $2.3 \%$ of discharges were longer than 21 days, but accounted for $18.6 \%$ of total inpatient days [45]. 
Our study identified several independent baseline associations with prolonged hospitalization. Other studies have similarly revealed that increasing age $[12,17,18,20,22,24,25,28-30,33,34,36,38-40,50]$, female gender [22,24,26,30,36,39,50], not being in a relationship, [52] being a current smoker [39], level of co-morbidity [11,12,14-16,18,22,26,40,42,44], weekend admissions [42], and the number of prior admissions $[25,32,44]$ were associated with prolonged hospitalization.

Finally, we found that prolonged hospitalization was independently associated with an increased risk of in-hospital death as well as a decreased likelihood of being discharged to home. Similar findings were found in the study by O'Sullivan et al. [44], which reported that prolonged hospitalization was associated with a 2.6-fold increase in in-hospital death and a lower likelihood of discharge to home, and Marfil-Garza et al. [42], who revealed a 3.6 fold increase in mortality in long-stay patients.

\subsection{Study Strengths and Limitations}

The strengths of our study include the large cohort that was complete for all of Victoria, adjustment for multiple co-variates and identification of readily measured baseline co-variates that are independently associated with prolonged hospitalization.

Limitations include the use of coding information and lack of information on advance care planning or end-of-life care. Specifically, many inpatients being palliated would have incurred longer LOS, and hence the association between prolonged hospitalization and in-hospital death was likely to have been bi-directionally causal. In addition, we cannot comment about the preventability of either the prolonged hospitalization or the associated increased risk of in-hospital death. It is possible that such patients may have not responded to appropriate treatment or alternatively, may have errors in diagnosis and/or treatment. Our study did not address specific diagnoses that contributed to prolonged LOS, which would be useful to policy-makers to decrease healthcare-related costs. However, our study does identify the groups in which interventions might be focused. For example, we found that patients who experience recurrent admissions and those not in a relationship are at increased risk of prolonged hospitalization. This suggests that increasing social supports in the community may reduce readmissions and/or timeliness of hospital discharge. The state of Victoria has a well-established primary health care network, and all hospitals have on-site outpatient facilities for review of patients following discharge. Enhancing the use of these services, as well as the interface between hospital and primary care, is likely to lead to reductions in hospital LOS and re-admissions.

Finally, the observed increase in mortality associated with prolonged hospitalization may, in part, relate to a longer period of subject surveillance. We are not able to comment on whether prolonged hospitalization was associated with an increased risk of mortality beyond hospital discharge.

\subsection{Implications for Clinicians and Policy-Makers}

We have found several associations between baseline patient characteristics and care delivery factors and prolonged hospitalization. While most of these factors are not modifiable, our findings permit the identification of patients at risk of prolonged hospitalization, who may be the target of interventions.

Patients experiencing prolonged hospitalization utilized four million bed days in Victoria over a two-year period. Even a reduction of the hospital length of stay by just $5 \%$ in such patients would save more than 104 thousand bed days annually in Victoria.

Our analysis has revealed that patients experiencing prolonged hospitalization experienced more frequent hospital admissions in the prior 12 months. Improvements in outpatient or primary care may assist in preventing some of these admissions or shorten their duration. In addition, such patients were more likely to require rehabilitation or to be discharged to residential care. Improved access to such facilities may correspondingly reduce the LOS in the acute care facility.

We also revealed that prolonged hospitalization was associated with an increased risk of death. It is possible that improved advance care planning and end-of-life care in this co-morbid, mostly medical, cohort may reduce hospital resource utilisation. 


\subsection{Areas for Future Research}

It is important to conduct further research to identify the clinical and process-related factors that are contributing to patients remaining in hospital, particularly those that may be modifiable. In addition, it will be important to evaluate whether there is sub-optimal end-of-life care and continuation of non-beneficial treatments in patients who experience prolonged hospitalization, particularly those who die in hospital.

\section{Conclusions}

Patients experiencing prolonged hospitalization comprise approximately one-tenth of multi-day admissions but utilize four-tenths of bed days. Such patients have different baseline characteristics and are at increased risk of in-hospital mortality. Further research is needed to identify factors contributing to prolonged hospitalization to improve patient outcomes and reduce resource utilization.

Supplementary Materials: The following are available online at http://www.mdpi.com/2077-0383/9/9/3055/s1, Table S1: Diagnostic related group (DRG) Codes for different specialties; Table S2: Uni-variate associations with prolonged hospital length of stay for patients hospitalized over two years in Victoria, Australia; Table S3: Associations with prolonged hospitalization ( $\geq 14$ days) for patients hospitalized over two years in Victoria, Australia who were discharged alive; Table S4: Uni-variate associations with in-hospital mortality for patients hospitalized over two years in Victoria, Australia; Table S5: Nature and destination of discharge among people who survived in hospital for patients hospitalized over two years in Victoria, Australia; Table S6: Independent associations with hospital discharge to home for patients hospitalized over two years in Victoria, Australia; Table S7: Summary of literature describing epidemiology of prolonged hospitalizations 2015 to 2019.

Author Contributions: Conceptualization, R.O.-A., D.L. and D.J.; Data curation, D.L.; Formal analysis, R.O.-A.; Methodology, D.J.; Writing-original draft, R.O.-A., D.L., J.M. and D.J.; Writing-review \& editing, R.O.-A., D.L., J.M. and D.J. All authors have read and agreed to the published version of the manuscript.

Funding: This research has received no external funding.

Acknowledgments: We wish to acknowledge the Centre for Victorian Data Linkage within the System Intelligence and Analytics Branch of the Victorian Department of Health and Human Services for assisting with the extraction and provision of the data necessary to conduct this study.

Conflicts of Interest: The authors declare no potential conflict of interest.

\section{References}

1. Divo, M.J.; Martinez, C.H.; Mannino, D.M. Ageing and the epidemiology of multimorbidity. Eur. Respir. J. 2014, 44, 1055-1068. [CrossRef] [PubMed]

2. Bergeron, E.; Lavoie, A.; Moore, L.; Clas, D.; Rossignol, M. Comorbidity and age are both independent predictors of length of hospitalization in trauma patients. Can. J. Surg. 2005, 48, 361-366. [PubMed]

3. Barnett, K.; Mercer, S.W.; Norbury, M.; Watt, G.; Wyke, S.; Guthrie, B. Epidemiology of multimorbidity and implications for health care, research, and medical education: A cross-sectional study. Lancet 2012, 380, 37-43. [CrossRef]

4. Chang, A.Y.; Skirbekk, V.F.; Tyrovolas, S.; Kassebaum, N.J.; Dieleman, J.L. Measuring population ageing: An analysis of the Global Burden of Disease Study 2017. Lancet Public Health 2019, 4, e159-e167. [CrossRef]

5. OECD. Health expenditure in hospitals. In Health at a Glance: Europe 2018; OECD Publishing: Paris, France; European Union: Brussels, Belgium, 2018; pp. 138-139. [CrossRef]

6. McKee, M. Reducing Hospital Beds. What Are the Lessons to Be Learned? European Observatory Health Systems and Policies: Geneva, Switzerland, 2004; p. 6.

7. Barisonzo, R.; Wiedermann, W.; Unterhuber, M.; Wiedermann, C.J. Length of stay as risk factor for inappropriate hospital days: Interaction with patient age and co-morbidity. J. Eval. Clin. Pract. 2013, 19, 80-85. [CrossRef]

8. Celik, Y.; Celik, S.S.; Bulut, H.D.; Khan, M.; Kisa, A. Inappropriate use of hospital beds: A case study of university hospitals in Turkey. World Hosp. Health Serv. 2001, 37, 6-13, 33-34.

9. Buttigieg, S.C.; Abela, L.; Pace, A. Variables affecting hospital length of stay: A scoping review. J. Health Organ. Manag. 2018, 32, 463-493. [CrossRef] 
10. Chakravarty, A.; Parmar, N.K.; Bhalwar, R. Inappropriate Use of Hospital Beds in a Tertiary Care Service Hospital. Med. J. Armed Forces India 2005, 61, 121-124. [CrossRef]

11. Agrawal, S.; Chen, L.; Tergas, A.I.; Hou, J.Y.; St Clair, C.M.; Ananth, C.V.; Hershman, D.L.; Wright, J.D. Identifying modifiable and non-modifiable risk factors associated with prolonged length of stay after hysterectomy for uterine cancer. Gynecol. Oncol. 2018, 149, 545-553. [CrossRef]

12. Agrawal, S.; Chen, L.; Tergas, A.I.; Hou, J.Y.; St Clair, C.M.; Ananth, C.V.; Neugut, A.I.; Hershman, D.L.; Wright, J.D. Characteristics associated with prolonged length of stay after hysterectomy for benign gynecologic conditions. Am. J. Obstet. Gynecol. 2018, 219, 89.e1-89.e15. [CrossRef]

13. Almogati, J.G.; Ahmed, E.O. Glycated Hemoglobin as a Predictor of the Length of Hospital Stay in Patients Following Coronary Bypass Graft Surgery in the Saudi Population. Braz. J. Cardiovasc. Surg. 2019, 34, $28-32$. [CrossRef] [PubMed]

14. Bateni, S.B.; Bold, R.J.; Meyers, F.J.; Canter, D.J.; Canter, R.J. Comparison of common risk stratification indices to predict outcomes among stage IV cancer patients with bowel obstruction undergoing surgery. J. Surg. Oncol. 2018, 117, 479-487. [CrossRef] [PubMed]

15. Belkin, N.; Jackson, B.M.; Foley, P.J.; Damrauer, S.M.; Kalapatapu, V.; Golden, M.A.; Fairman, R.M.; Kelz, R.R.; Wang, G.J. Length of Stay after Thoracic Endovascular Aortic Repair Depends on Indication and Acuity. Ann. Vasc. Surg. 2019, 55, 157-165. [CrossRef] [PubMed]

16. Carter, J.; Elliott, S.; Kaplan, J.; Lin, M.; Posselt, A.; Rogers, S. Predictors of hospital stay following laparoscopic gastric bypass: Analysis of 9593 patients from the National Surgical Quality Improvement Program. Surg. Obes. Relat. Dis. 2015, 11, 288-294. [CrossRef]

17. Casillas-Berumen, S.; Rojas-Miguez, F.A.; Farber, A.; Komshian, S.; Kallish, J.A.; Rybin, D.; Goros, G.; Siracuse, J.J. Patient and Aneurysm Characteristics Predicting Prolonged Length of Stay after Elective Open AAA Repair in the Endovascular Era. Vasc. Endovascular. Surg. 2018, 52, 5-10. [CrossRef]

18. Coelho, R.F.; Cordeiro, M.D.; Padovani, G.P.; Localli, R.; Fonseca, L.; Junior, J.P.; Guglielmetti, G.B.; Sroughi, M.; Naha, W.C. Predictive factors for prolonged hospital stay after retropubic radical prostatectomy in a high-volume teaching center. Int. Braz. J. Urol. 2018, 44, 1089-1105. [CrossRef]

19. Crisafulli, E.; Ielpo, A.; Barbeta, E.; Ceccato, A.; Huerta, A.; Gabarrus, A.; Soler, N.; Chetta, A.; Torres, A. Clinical variables predicting the risk of a hospital stay for longer than 7 days in patients with severe acute exacerbations of chronic obstructive pulmonary disease: A prospective study. Respir. Res. 2018, $19,261$. [CrossRef]

20. Dasenbrock, H.H.; Liu, K.X.; Devine, C.A.; Chavakula, V.; Smith, T.R.; Gormley, W.B.; Dunn, I.F. Length of hospital stay after craniotomy for tumor: A National Surgical Quality Improvement Program analysis. Neurosurg. Focus 2015, 39, E12. [CrossRef]

21. Dunn, J.C.; Lanzi, J.; Kusnezov, N.; Bader, J.; Waterman, B.R.; Belmont, P.J., Jr. Predictors of length of stay after elective total shoulder arthroplasty in the United States. J. Shoulder Elbow Surg. 2015, 24, 754-759. [CrossRef]

22. Fletcher, R.; Deal, R.; Kubasiak, J.; Torquati, A.; Omotosho, P. Predictors of Increased Length of Hospital Stay Following Laparoscopic Sleeve Gastrectomy from the National Surgical Quality Improvement Program. J. Gastrointest. Surg. 2018, 22, 274-278. [CrossRef]

23. Goltzman, G.; Perl, S.; Cohen, L.; Avivi, E.; Rapoport, M.J. Single Admission C-reactive protein Levels as a Sole Predictor of Patient Flow and Clinical Course in a General Internal Medicine Department. Isr. Med. Assoc. J. 2019, 21, 686-691. [PubMed]

24. Inneh, I.A.; Iorio, R.; Slover, J.D.; Bosco, J.A., 3rd. Role of Sociodemographic, Co-morbid and Intraoperative Factors in Length of Stay Following Primary Total Hip Arthroplasty. J. Arthroplast. 2015, 30, $2092-2097$. [CrossRef] [PubMed]

25. Kaoutzanis, C.; Leichtle, S.W.; Mouawad, N.J.; Welch, K.B.; Lampman, R.M.; Wahl, W.L.; Cleary, R.K. Risk factors for postoperative wound infections and prolonged hospitalization after ventral/incisional hernia repair. Hernia 2015, 19, 113-123. [CrossRef] [PubMed]

26. Lakomkin, N.; Goz, V.; Lajam, C.M.; Iorio, R.; Bosco, J.A., 3rd. Higher Modified Charlson Index Scores Are Associated with Increased Incidence of Complications, Transfusion Events, and Length of Stay Following Revision Hip Arthroplasty. J. Arthroplast. 2017, 32, 1121-1124. [CrossRef] [PubMed]

27. Lakomkin, N.; Zuckerman, S.L.; Stannard, B.; Montejo, J.; Sussman, E.S.; Virojanapa, J.; Kuzmik, G.; Goz, V.; Hadjipanayis, C.G.; Cheng, J.S. Preoperative Risk Stratification in Spine Tumor Surgery: A Comparison of the Modified Charlson Index, Frailty Index, and ASA Score. Spine 2019, 44, 782-787. [CrossRef] 
28. Lee, S.Y.; Lee, S.H.; Tan, J.H.H.; Foo, H.S.L.; Phan, P.H.; Kow, A.W.; Lwin, S.; Seah, P.M.; Mordiffi, S.T. Factors associated with prolonged length of stay for elective hepatobiliary and neurosurgery patients: A retrospective medical record review. BMC Health Serv. Res. 2018, 18, 5. [CrossRef] [PubMed]

29. McGirt, M.J.; Parker, S.L.; Chotai, S.; Pformiller, D.; Sorenson, J.M.; Foley, K.; Ashler, A.L. Predictors of extended length of stay, discharge to inpatient rehab, and hospital readmission following elective lumbar spine surgery: Introduction of the Carolina-Semmes Grading Scale. J. Neurosurg. Spine 2017, 27, 382-390. [CrossRef]

30. Menendez, M.E.; Baker, D.K.; Fryberger, C.T.; Ponce, B.A. Predictors of extended length of stay after elective shoulder arthroplasty. J. Shoulder Elbow Surg. 2015, 24, 1527-1533. [CrossRef]

31. Petis, S.M.; Howard, J.L.; Lanting, B.A.; Somerville, L.E.; Vasarhelyi, E.M. Perioperative Predictors of Length of Stay After Total Hip Arthroplasty. J. Arthroplast. 2016, 31, 1427-1430. [CrossRef]

32. Quintana, J.M.; Unzurrunzaga, A.; Garcia-Gutierrez, S.; Gonzalez, N.; Lafuente, I.; Bare, M.; de Larrea, N.F.; Esteban, C. Predictors of Hospital Length of Stay in Patients with Exacerbations of COPD: A Cohort Study. J. Gen. Intern. Med. 2015, 30, 824-831. [CrossRef]

33. Rana, A.; Witte, E.D.; Halazun, K.J.; Sood, G.K.; Mindikoglu, A.L.; Sussmann, N.L.; Vierling, J.M.; Kuet, M.L.; Galvan, N.T.; Cotton, R.T.; et al. Liver transplant length of stay (LOS) index: A novel predictive score for hospital length of stay following liver transplantation. Clin. Transplant. 2017, 31, e13141. [CrossRef] [PubMed]

34. Thomas, W.W.; Brant, J.; Chen, J.; Coblens, O.; Fischer, J.P.; Newman, J.G.; Chalian, A.A.; Shanti, R.M.; Cannady, S.B. Clinical Factors Associated with Reoperation and Prolonged Length of Stay in Free Tissue Transfer to Oncologic Head and Neck Defects. JAMA Facial Plast. Surg. 2018, 20, 154-159. [CrossRef] [PubMed]

35. Tsilimigras, D.I.; Hyer, J.M.; Moris, D.; Sahara, K.; Bagante, F.; Guglielmi, A.; Aldrighetti, A.; Alexandrescu, S.; Marques, H.P.; Shen, F.; et al. Prognostic utility of albumin-bilirubin grade for short- and long-term outcomes following hepatic resection for intrahepatic cholangiocarcinoma: A multi-institutional analysis of 706 patients. J. Surg. Oncol. 2019, 120, 206-213. [CrossRef]

36. Velagapudi, P.; Kolte, D.; Ather, K.; Khera, S.; Gupta, T.; Gordon, P.C.; Aronow, H.D.; Kirtane, A.J.; Abott, J.D. Temporal Trends and Factors Associated with Prolonged Length of Stay in Patients With ST-Elevation Myocardial Infarction Undergoing Primary Percutaneous Coronary Intervention. Am. J. Cardiol. 2018, 122, 185-191. [CrossRef] [PubMed]

37. Wang, G.J.; Jackson, B.M.; Foley, P.J.; Dramrauer, S.M.; Kalapatapu, V.; Golden, M.A.; Fairman, R.M. Treating Peripheral Artery Disease in the Wake of Rising Costs and Protracted Length of Stay. Ann. Vasc. Surg. 2017, 44, 253-260. [CrossRef] [PubMed]

38. Wasfy, J.H.; Kennedy, K.F.; Masoudi, F.A.; Ferris, T.G.; Arnold, S.V.; Kini, V.; Peterson, P.; Curtis, J.P.; Amin, A.P.; Bradley, S.M.; et al. Predicting Length of Stay and the Need for Postacute Care After Acute Myocardial Infarction to Improve Healthcare Efficiency. Circ. Cardiovasc. Qual. Outcomes 2018, 11, e004635. [CrossRef]

39. Winemaker, M.; Petruccelli, D.; Kabali, C.; de Beer, J. Not all total joint replacement patients are created equal: Preoperative factors and length of stay in hospital. Can. J. Surg. 2015, 58, 160-166. [CrossRef]

40. Zhan, H.; Guo, R.; Xu, H.; Liu, X.; Yu, X.; Xu, Q.; Chen, H.; Dai, M.; Zhang, B. Hospital length of stay following first-time elective open posterior lumbar fusion in elderly patients: A retrospective analysis of the associated clinical factors. Medicine 2019, 98, e17740. [CrossRef]

41. Lisk, R.; Uddin, M.; Parbhoo, A.; Yeong, K.; Fluck, D.; Sharma, P.; Lean, M.E.; Shan, T.S. Predictive model of length of stay in hospital among older patients. Aging Clin. Exp. Res. 2019, 31, 993-999. [CrossRef]

42. Marfil-Garza, B.A.; Belaunzaran-Zamudio, P.F.; Gulias-Herrero, A.; Zuniga, A.C.; Caro-Vega, Y.; Kershenobich-Stalnikowitz, D.; Sifuentes-Osornio, J. Risk factors associated with prolonged hospital length-of-stay: 18-year retrospective study of hospitalizations in a tertiary healthcare center in Mexico. PLoS ONE 2018, 13, e0207203. [CrossRef]

43. Nguyen, A.T.; Nguyen, T.X.; Nguyen, T.N.; Nguyen, T.H.; Pham, T.; Cumming, R.; Hilmer, S.N.; $\mathrm{Vu}, \mathrm{H}$.T. The impact of frailty on prolonged hospitalization and mortality in elderly inpatients in Vietnam: A comparison between the frailty phenotype and the Reported Edmonton Frail Scale. Clin. Interv. Aging 2019, 14, 381-388. [CrossRef] [PubMed] 
44. O'Sullivan, K.; Martensson, J.; Robbins, R.; Farley, K.J.; Johnson, D.; Jones, D. Epidemiology of long-stay patients in a university teaching hospital. Intern. Med. J. 2017, 47, 513-521. [CrossRef] [PubMed]

45. Anderson, M.E.; Glasheen, J.J.; Anoff, D.; Pierce, R.; Capp, R.; Jones, C.D. Understanding predictors of prolonged hospitalizations among general medicine patients: A guide and preliminary analysis. J. Hosp. Med. 2015, 10, 623-626. [CrossRef] [PubMed]

46. Services VSGHaH. Victorian Admitted Episodes Dataset Manual 2019-2020. $2019 . \quad$ Available online: https://www2.health.vic.gov.au/about/publications/policiesandguidelines/Victorian-AdmittedEpisodes-Dataset-manual-2019-2020 (accessed on 11 January 2020).

47. Services VSGHaH. Victorian Emergency Minimum Dataset (VEMD). 2019. Available online: https://www2.health.vic.gov.au/hospitals-and-health-services/data-reporting/health-data-standardssystems/data-collections/vemd (accessed on 13 January 2020).

48. Charlson, M.E.; Pompei, P.; Ales, K.L.; MacKenzie, C.R. A new method of classifying prognostic comorbidity in longitudinal studies: Development and validation. J. Chronic Dis. 1987, 40, 373-383. [CrossRef]

49. World Health Organization. Proposed Working Definition of an Older Person in Africa for the MDS Project. 2002. Available online: https://www.who.int/healthinfo/survey/ageingdefnolder/en/ (accessed on 11 January 2020).

50. Crawford, T.C.; Magruder, J.T.; Grimm, J.C.; Suarez-Pierre, A.; Patel, N.; Sciortino, C.M.; Zehr, K.J.; Mandal, K.; Tedford, R.J.; Russell, S.D.; et al. A Comprehensive Risk Score to Predict Prolonged Hospital Length of Stay After Heart Transplantation. Ann. Thorac. Surg. 2018, 105, 83-90. [CrossRef] [PubMed]

51. Barba, R.; Marco, J.; Canora, J.; Plaza, S.; Juncos, S.N.; Hinojosa, J.; Bailon, M.M.; Zapatero, A. Prolonged length of stay in hospitalized internal medicine patients. Eur. J. Intern. Med. 2015, 26, 772-775. [CrossRef]

52. Agosti, P.; Tettamanti, M.; Vella, F.S.; Suppressa, P.; Pasina, L.; Franchi, C.; Nobili, A.; Mannucci, P.M.; Sabba, C. REPOSI Investigators. Living alone as an independent predictor of prolonged length of hospital stay and non-home discharge in older patients. Eur. J. Intern. Med. 2018, 57, 25-31. [CrossRef]

(C) 2020 by the authors. Licensee MDPI, Basel, Switzerland. This article is an open access article distributed under the terms and conditions of the Creative Commons Attribution (CC BY) license (http://creativecommons.org/licenses/by/4.0/). 